\title{
The phenomenon of "permanent" electrochemical promotion of catalysis (P-EPOC)
}

\author{
Cyril Falgairette $\cdot$ Arnaud Jaccoud $\cdot$ \\ György Fóti · Christos Comninellis
}

Received: 29 October 2007/Revised: 28 February 2008/Accepted: 19 March 2008/Published online: 12 April 2008

(C) Springer Science+Business Media B.V. 2008

\begin{abstract}
The phenomenon of electrochemical promotion of catalysis (EPOC) is most often fully reversible. Subsequent to long-lasting polarization, however, the new steady-state open-circuit catalytic activity after current interruption may remain significantly higher than that before polarization. This phenomenon, discovered in our laboratory in the late 1990s and called permanent electrochemical promotion of catalysis (P-EPOC), has been observed on both oxide $\left(\mathrm{IrO}_{2}, \mathrm{RuO}_{2}\right)$ and metal $(\mathrm{Rh})$ catalysts. P-EPOC is out of the state-of-the-art model of reversible EPOC, which considers the gas-exposed catalyst surface as the unique location of charge storage via backspillover of electrochemically generated promoter species accompanied by their consumption in the catalytic reaction ('sacrificial' promoter). Double step chronoamperometric and linear sweep voltammetric characterization of Pt catalyst deposited on YSZ solid electrolyte revealed the existence of a somewhat delayed oxygen storage occurring at the vicinity of the catalyst/electrolyte interface during prolonged anodic polarization. It is proposed that oxygen stored at this location, hidden for the reactant, and then released during relaxation was at the origin of $\mathrm{P}$ EPOC on the Pt/YSZ catalyst observed in catalytic combustion of ethylene with oxygen. The effect of this 'hidden' promoter on the catalytic reaction rate was found to be highly non-Faradaic.
\end{abstract}

\footnotetext{
C. Falgairette · A. Jaccoud · G. Fóti $(\square) \cdot$ C. Comninellis $(\square)$ Institute of Chemical Sciences and Engineering, Ecole Polytechnique Fédérale de Lausanne (EPFL), 1015 Lausanne, Switzerland

e-mail: gyorgy.foti@epfl.ch

C. Comninellis

e-mail: christos.comninellis@epfl.ch
}

Keywords EPOC - Permanent promotion - Pt catalyst . Oxygen storage

\section{Introduction}

In the late 1980s Vayenas and co-workers [1, 2] have shown that the catalytic activity of metal catalysts deposited on solid electrolytes can be altered by applying potential or current to the catalyst/electrolyte interface. According to these authors this behavior is reversible and the catalyst restores its initial activity, typically within a few tens of minutes, after current interruption. This phenomenon is known as electrochemical promotion of catalysis (EPOC) or as non-Faradaic electrochemical modification of catalytic activity (NEMCA).

Recent measurements in our laboratory demonstrated that the reversibility of this phenomenon depends strongly on the duration of polarization. In fact, for prolonged polarization times (few hours) the catalytic reaction rate after current interruption remains higher than the value before current application. This behavior has been reported as 'permanent electrochemical promotion' (P-EPOC).

Figure 1 shows the influence of the anodic polarization time on the catalytic rate of ethylene combustion over $\mathrm{IrO}_{2}$ catalyst deposited on yttria-stabilized zirconia (YSZ). Initially, the circuit is open and the catalytic rate is very low. Upon current application the reaction rate increases to a steady-state value 3.5 times higher than the initial opencircuit rate. This increase is two orders of magnitude higher than the rate of $\mathrm{O}^{2-}$ supply to the $\mathrm{IrO}_{2}$ catalyst indicating that we are not dealing with an electrochemical reaction but with a purely catalytic reaction enhanced by current application. The interruption of current after polarization for a few minutes (curve a in Fig. 1) results in a decrease of 


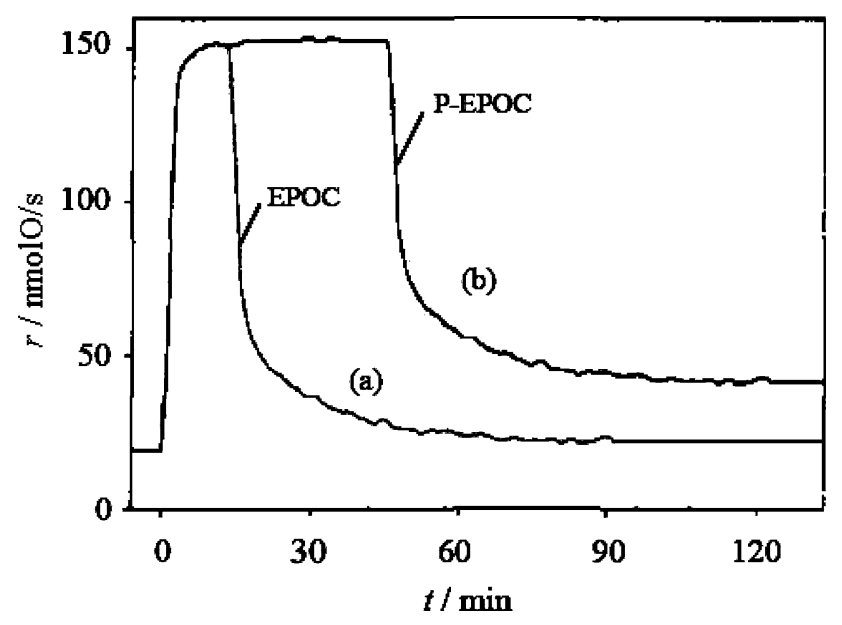

Fig. 1 Polarization and relaxation transients of the rate of ethylene combustion on $\mathrm{IrO}_{2} / \mathrm{YSZ}$ catalyst due to current application $(300 \mu \mathrm{A})$ for two different polarization times: (a) short polarization to give reversible EPOC and (b) long polarization to give P-EPOC. $T=380{ }^{\circ} \mathrm{C}, p_{\mathrm{O}_{2}}=17 \mathrm{kPa}, p_{\mathrm{C}_{2} \mathrm{H}_{4}}=140 \mathrm{~Pa}$

the reaction rate to reach the same value as before current application. This is the phenomenon of EPOC reported by Vayenas et al. [1-3]. However, in case of prolonged anodic polarization (curve b) the catalytic reaction rate after current interruption stabilizes at a value, which is about two times higher than the initial catalytic rate measured prior to current application. Thus, the steady-state open-circuit catalytic activity of the $\mathrm{IrO}_{2}$ catalyst for complete oxidation of ethylene has been enhanced by the electrochemical treatment. This is the phenomenon of P-EPOC reported by Nicole et al. [4]. P-EPOC has been observed also on $\mathrm{RuO}_{2}$ [5] and Rh [6] catalysts, both interfaced with YSZ. In this work, the P-EPOC phenomenon has been investigated in the complete combustion of ethylene on $\mathrm{Pt}$ catalyst deposited on YSZ. Electrochemical and reaction rate measurements allowed proposing a model based on oxygen storage acting as 'hidden' promoter in the P-EPOC phenomenon.

\section{Experimental}

Two sorts of three-electrode Pt/YSZ electrochemical cells, both of single-pellet type, were used. In the cell for electrochemical characterization, all three electrodes were platinum films deposited onto a $1.3 \mathrm{~mm}$ thick YSZ ( $8 \mathrm{~mol} \%$ ) pellet by screen-printing of a paste, composed of $65 \mathrm{wt} \%$ of $1 \mu \mathrm{m}$ particle size platinum powder (Fluka), $11 \mathrm{wt} \%$ of $1 \mu \mathrm{m}$ particle size $\mathrm{YSZ}\left(8 \mathrm{~mol} \% \mathrm{Y}_{2} \mathrm{O}_{3}\right.$ in $\mathrm{ZrO}_{2}$, Tosoh) and $24 \%$ of a polyvinyl pyrrolidone solution ( $2 \%$ in isopropanol, Fluka), followed by sintering at $1,400{ }^{\circ} \mathrm{C}$ in air to give a film thickness of $15 \mu \mathrm{m}$. The resulting deposits of $0.08 \mathrm{~cm}^{2}$ geometric surface area each are composed of
$62 \mathrm{vol} . \%$ of platinum and $38 \mathrm{vol} . \%$ of YSZ and they are highly porous. No morphological change has been observed due to prolonged use and/or polarization during working months. In the cell used for catalytic measurements, the counter and the reference electrodes were pasted gold films (Gwent C70219R4) fired at $550{ }^{\circ} \mathrm{C}$ in air while the working electrode was a platinum film deposited onto a $1 \mathrm{~mm}$ thick YSZ ( $8 \mathrm{~mol} \%$ ) pellet by non-reactive magnetron sputtering of platinum at ambient temperature in argon atmosphere followed by heat treatment at $700{ }^{\circ} \mathrm{C}$ in air. The size of the electrodes was $7 \times 5 \mathrm{~mm}$, giving a geometric surface of $0.35 \mathrm{~cm}^{2}$. More details on cell preparation are given elsewhere [7].

The reactor for both electrochemical and catalytic measurements was of single-chamber type meaning that all electrodes were exposed to the same atmosphere. It consisted of a quartz tube of $90 \mathrm{~mL}$ volume closed with a stainless steel cap, and it worked under atmospheric pressure. The single-pellet three-electrode cells were suspended in the reactor with the three gold wires serving as electrical contacts to the electrodes. The temperature in the reactor was measured with a $\mathrm{K}$-type $(\mathrm{NiCr}-\mathrm{Ni})$ thermocouple placed in proximity of the surface of the working electrode. Gold wires and thermocouple were led out the reactor through a four-hole alumina tube (Degussa). The reactor was put into a furnace (XVA271, Horst) equipped with a heat control system (HT30, Horst). Measurements were carried out under continuous gas flow of $200 \mathrm{~mL} \mathrm{~min}^{-1}$ fed by mass flow controllers (E-5514-FA, Bronkhorst). Electrochemical measurements were made in $20 \mathrm{kPa} \mathrm{O}_{2}$ at $450{ }^{\circ} \mathrm{C}$, while catalytic experiments were conducted at $525^{\circ} \mathrm{C}$ in a slightly oxidizing reactive gas mixture containing $0.25 \mathrm{kPa} \mathrm{C}_{2} \mathrm{H}_{4}$ and $1 \mathrm{kPa} \mathrm{O}$. The gas sources were Carbagas certified standards of $\mathrm{O}_{2}(99.95 \%)$ and $\mathrm{C}_{2} \mathrm{H}_{4}$ (99.95\%) supplied, respectively, as a $20 \%$ and $1 \%$ mixture in $\mathrm{He}(99.996 \%)$. Balance was helium of $99.996 \%$ purity.

For the chronoamperometric and voltammetric measurements a scanning potentiostat-galvanostat (Autolab, Model PGSTAT30, EcoChemie) was used. Electrochemical promotion experiments were realized in potentiostatic mode of operation using a galvanostat-potentiostat (EG\&G PAR, Model 362), and $\mathrm{CO}_{2}$ production of the catalytic oxidation of ethylene was monitored on-line using an IR analyzer (Horiba PIR 2000).

\section{Results}

The Pt/YSZ electrode was first characterized by electrochemical methods using chronoamperometry $[8,9]$ and linear sweep voltammetry [8-10] in $\mathrm{O}_{2}$-containing atmosphere at $450{ }^{\circ} \mathrm{C}$. Then, used as catalyst and electrode at the same time, the catalytic activity of Pt deposited onto 


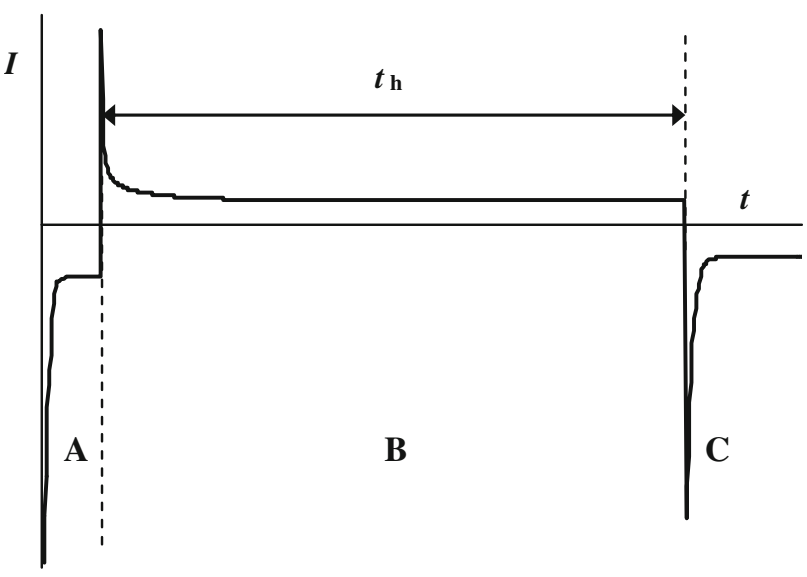

Fig. 2 Double step chronoamperometry in the $\mathrm{O}_{2}(\mathrm{~g}), \mathrm{Pt} / \mathrm{YSZ}$ system. Schematic illustration of the current response to the subsequent potential steps: (A) cathodic pretreatment, (B) anodic polarization, and $(\mathbf{C})$ cathodic discharge

YSZ was measured both under open-circuit and anodically promoted conditions at $525{ }^{\circ} \mathrm{C}$, the model catalytic reaction being the combustion of ethylene with oxygen.

\subsection{Electrochemical measurements}

Double-step chronoamperometric measurements were made using a potential program composed of a pretreatment step and two measurement steps (see Fig. 2). The cathodic pretreatment step (A) aims to reduce any residual oxidized species and so ensuring identical reproducible initial state before each experiment. It consisted of a polarization at a constant potential of $E_{\text {pre }}=-400 \mathrm{mV}$ for $t_{\text {pre }}=60 \mathrm{~s}$. In the first measurement step (B) a constant anodic holding potential, $E_{\mathrm{h}}$, was applied for varying holding times, $t_{\mathrm{h}}$. Then, in the second measuring step $(\mathrm{C})$, the cell was discharged by setting the potential to a constant cathodic potential, $E_{\mathrm{dis}}=-300 \mathrm{mV}$, held for $t_{\mathrm{dis}}=150 \mathrm{~s}$. This step aims to reduce the species formed during the preceding anodic potential holding step. During the two measuring steps, the current passing through the cell was recorded as a function of time.

The chronoamperometric transients of the anodic polarization step were composed of two parts. In the first transient part the current decreased with a time constant of a few tens of seconds to reach a non-zero steady-state value characteristic to the second part. The time constant and the current, both transient and steady-state, depended on the anodic holding potential [8]. The non-zero steady-state current indicates clearly the existence of an anodic Faradaic process under positive polarization, which persists at infinite time. This process is attributed mainly to the oxygen evolution reaction (Eq. 1), which consists of discharge of $\mathrm{O}^{2-}$ ion of the solid electrolyte:
$\mathrm{O}^{2-} \rightarrow 1 / 2 \mathrm{O}_{2}+2 \mathrm{e}^{-}$

However, it cannot be ruled out that the observed finite steady-state current is also contributed to by other Faradaic reactions related to charge storage, as will be shown below.

On the other hand, there is also a clear evidence of a Faradaic contribution to the transient current. In fact, the experimentally found time constant is several orders of magnitude higher than that of double layer charging of a blocking Pt/YSZ interface in the given cell, estimated with the ohmic resistance of the electrolyte $\left(R_{\mathrm{el}}=980 \Omega\right.$ measured by impedance spectroscopy), with the capacitance of the double layer $\left(C_{\mathrm{dl}}=50 \mu \mathrm{F} \mathrm{cm}{ }^{-2}\right.$ [11] $)$ and with the geometric surface of the electrode $\left(S=0.08 \mathrm{~cm}^{2}\right)$ to give $\tau=R_{\mathrm{el}} \cdot C_{\mathrm{dl}} \cdot \mathrm{S}=4 \mathrm{~ms}$. Even with a roughness factor (meaning here the ratio of the $\mathrm{Pt} / \mathrm{YSZ}$ interface area to the geometric area) estimated to be as high as ten, the time constant of double layer charging would remain by at least two orders of magnitude below the experimentally obtained value. This indicates a contribution from another phenomenon, which is not only much slower than the electrostatic double layer charging but is also at the origin of the pseudocapacity of the electrode which is by orders of magnitude higher than the electrostatic double layer capacity.

Figure 3 shows the current transients during cathodic discharge subsequent to anodic polarization at $E_{\mathrm{h}}=+100 \mathrm{mV}$ for varying holding time, $t_{\mathrm{h}}$. For short holding time $\left(t_{\mathrm{h}}=5 \mathrm{~min}\right)$, a relatively fast decay of the cathodic current is observed, approaching a steady-state value $(-30 \mu \mathrm{A})$ after about $10 \mathrm{~s}$. The other curves also show a rapid decay in the initial stage of the cathodic current $(t<10 \mathrm{~s})$, but as $t_{\mathrm{h}}$ increases, more and more time is needed to reach the steady-state current. In particular, after a long polarization time of $t_{\mathrm{h}}=80 \mathrm{~min}, 80 \mathrm{~s}$ are necessary to reach the steady-state. This suggests that, during anodic polarization, charge is stored via a Faradaic process, and this is not limited to the period of anodic current decay but is extended to the steady state region, in parallel to the main reaction of $\mathrm{O}_{2}$ evolution.

The charges involved in the storage process were determined by integration of the chronoamperometric transients using the final steady-state currents as baseline to give values of $Q_{\text {charging }}$ and $Q_{\text {discharging }}$ in the anodic and the cathodic step, respectively. The value of $Q_{\text {discharging }}$ is considered as the charge effectively stored during the anodic step. Figure 4 shows the values of $Q_{\text {charging }}$ and $Q_{\text {discharging }}$ obtained by integration of the $I-t$ curves in Fig. 3 as a function of the anodic holding time in the range of 5-80 min. Contrary to $Q_{\text {charging, }}$, which is independent of $t_{\mathrm{h}}, Q_{\text {discharging }}$ increases with increasing $t_{\mathrm{h}}$. At short holding time $\left(t_{\mathrm{h}}=5 \mathrm{~min}\right)$ the two charges are comparable, meaning that the charge apparently stored during the anodic 


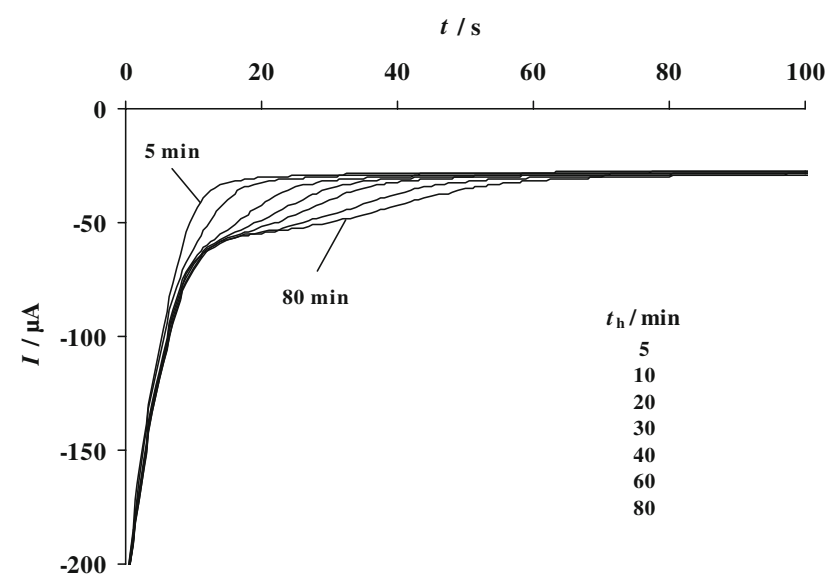

Fig. 3 Double step chronoamperometry in the $\mathrm{O}_{2}(\mathrm{~g}), \mathrm{Pt} / \mathrm{YSZ}$ system. Effect of the holding time, $t_{\mathrm{h}}$, at the anodic potential of $E_{\mathrm{h}}=100 \mathrm{mV}$ on the current transients obtained during the cathodic discharging step. $E_{\text {dis }}=-300 \mathrm{mV}, T=450{ }^{\circ} \mathrm{C}, p_{\mathrm{O}_{2}}=20 \mathrm{kPa}$

charging step represents the totality of the stored charge measured by its release during the discharging step. However, as $t_{\mathrm{h}}$ increases, $Q_{\text {discharging }}$ exceeds $Q_{\text {charging }}$, meaning that the electrode has stored more charge than expected from the anodic $I-t$ curve. The difference between these two charges, called extra charge, $Q_{\text {extra }}\left(=Q_{\text {discharging }}-Q_{\text {charging }}\right)$ was found to be a linear function of $t_{\mathrm{h}}{ }^{1 / 2}$ (see inset of Fig. 4), suggesting a diffusion-controlled process. The linear extrapolation, however, does not pass through the origin of the plot, having an intersection of $t_{\mathrm{h}}{ }^{1 / 2}=10 \mathrm{~s}^{1 / 2}$ at $Q_{\text {extra }}=0$. This means that there is a delay of roughly $100 \mathrm{~s}$ after the onset of the anodic polarization before extra charge is stored with a $t_{\mathrm{h}}{ }^{1 / 2}$ kinetic rule. Then this storage process goes on throughout the anodic polarization step, including the period of steadystate current. Hence, a certain fraction of the apparent steady-state current is in fact stored as extra charge. One

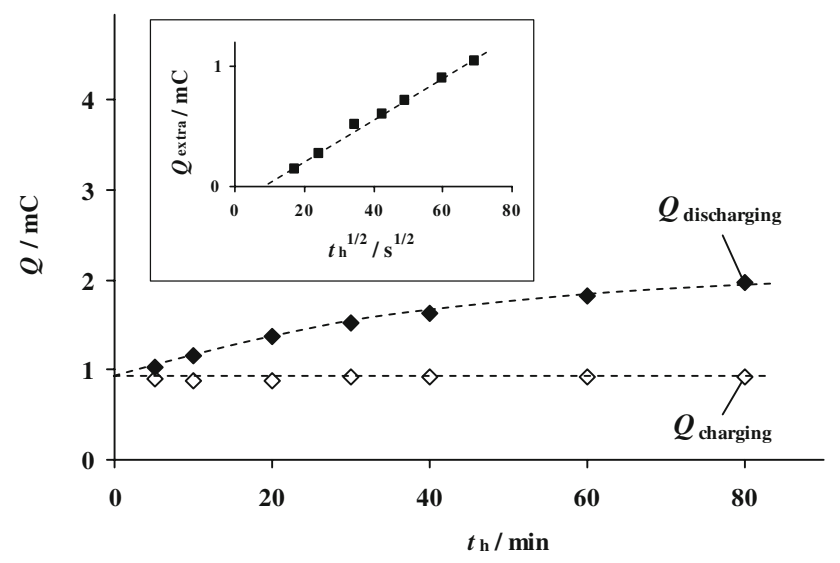

Fig. 4 Double step chronoamperometry in the $\mathrm{O}_{2}(\mathrm{~g}), \mathrm{Pt} / \mathrm{YSZ}$ system. Effect of the anodic holding time, $t_{\mathrm{h}}$, on $Q_{\text {charging }}(\diamond)$ and $Q_{\text {discharging }}$ $(\diamond)$. The inset shows the $Q_{\text {extra }}$ vs $t_{\mathrm{h}}{ }^{1 / 2}$ plot, where $Q_{\text {extra }}=Q_{\text {discharging }}$ - $Q_{\text {charging. }}$ Experimental conditions as in Fig. 3 can define a charge storage yield as the ratio between $Q_{\text {extra }}$ and the total charge passing as stead-state current. In the present case, the obtained yield lies between $1.5 \%$ and $6 \%$ and tends to decrease with increasing $t_{\mathrm{h}}$.

The above observations are in full agreement with linear sweep voltammetric measurements, analogous to those of a previous work [10], but performed with very long anodic potential holding. The measurements consisted of a cathodic pretreatment step, identical to that of the chronoamperometric experiments discussed above, and an anodic potential holding step at $E_{\mathrm{h}}=+100 \mathrm{mV}$ for different holding times between 1 and 2,000 min, followed by a linear potential sweep down to a cathodic potential of $-800 \mathrm{mV}$ with a scan rate of $10 \mathrm{mV} \mathrm{s}^{-1}$ (first cathodic scan). Figure 5 shows a typical voltammetric response of the Pt/YSZ electrode. At a very short holding time (1 $\mathrm{min})$, two distinct reduction peaks appear with comparable sizes at about -150 and $-250 \mathrm{mV}$, respectively. With increasing $t_{\mathrm{h}}$, the second peak increases more rapidly than the first. By further increasing the holding time, a third peak-not observed at very low $t_{\mathrm{h}}$-appears progressively. One can discern the third peak from about $t_{\mathrm{h}}=10 \mathrm{~min}$. At higher holding times $\left(t_{\mathrm{h}}>80 \mathrm{~min}\right)$, the first and second peaks have stopped growing, but the third peak shows no sign of saturation. This appears clearly in Fig. 6 which reports the charge for each peak as a function of the holding time. The charges were obtained by peak integration and given in terms of equivalent amount of oxygen atoms (atom $\mathrm{O} \mathrm{cm}{ }^{-2}$ ) for the three peaks $\left(N_{1}, N_{2}\right.$ and $N_{3}$, respectively), calculated with the exchange of two electrons and referred to unit geometrical surface area of the deposit. The amount involved in the first peak increases from the beginning and reaches saturation in about $10 \mathrm{~min}$. Similarly, the second peak starts to grow from the beginning suggesting two parallel processes. Also the area of the second peak tends

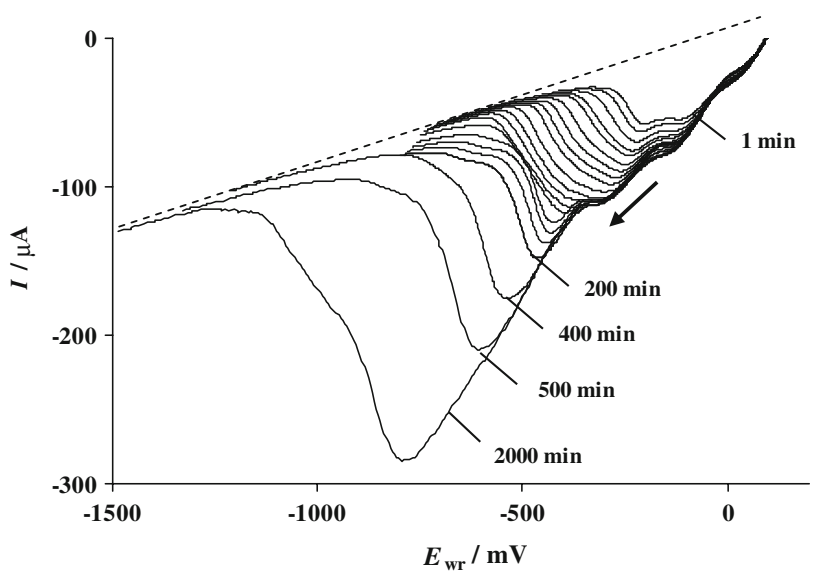

Fig. 5 Linear sweep voltammetry in the $\mathrm{O}_{2}(\mathrm{~g}), \mathrm{Pt} / \mathrm{YSZ}$ system. Effect of the holding time, $t_{\mathrm{h}}$, at $E_{\mathrm{h}}=100 \mathrm{mV}$ on the first cathodic scan. $T=450{ }^{\circ} \mathrm{C}, p_{\mathrm{O}_{2}}=20 \mathrm{kPa}, v=10 \mathrm{mV} / \mathrm{s}$. Dashed line shows the baseline used for peak area integration 


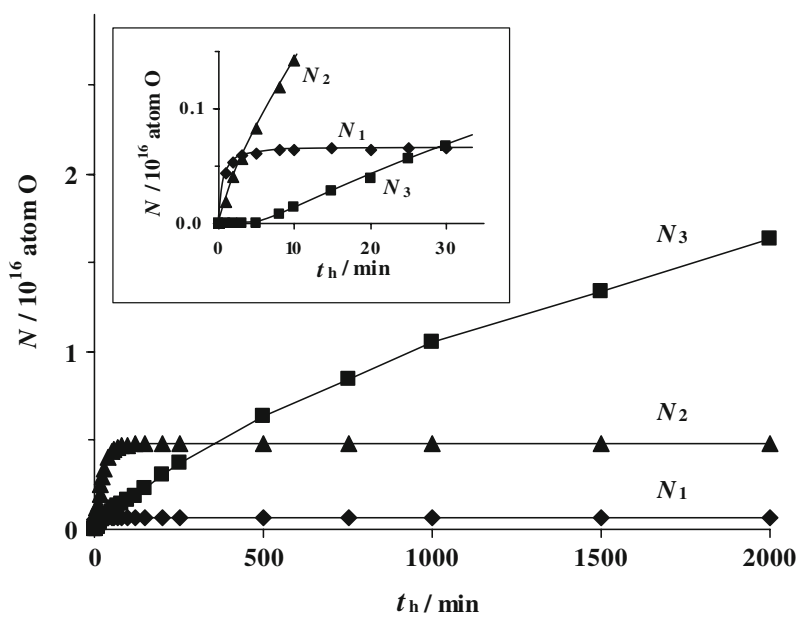

Fig. 6 Linear sweep voltammetry in the $\mathrm{O}_{2}(\mathrm{~g}), \mathrm{Pt} / \mathrm{YSZ}$ system. Effect of holding time, $t_{\mathrm{h}}$, at $E_{\mathrm{h}}=100 \mathrm{mV}$ on the amount of injected oxygen related to the first, second and third peaks. The amount of oxygen atoms, $N$, is calculated assuming the exchange of two electrons. The inset shows a zoom on the domain of short holding time. Experimental conditions as in Fig. 5

to saturation, at a value of about seven times higher than that of the first peak, in about 80 min of holding time. As seen in the inset of Fig. 6, the third peak starts growing when the first peak has reached saturation. Therefore this process seems to be consecutive to that of the first peak. The third peak then grows continuously and, during holding times as long as 2,000 min, there is no clear sign of any tendency to peak area saturation.

Similarly to the accumulation of the extra charge in the double-step chronoamperometric experiments (see inset of Fig. 4), the increase in the area of the third voltammetric peak $\left(N_{3}\right)$ also follows $t_{\mathrm{h}}{ }^{1 / 2}$ kinetics, again suggesting a diffusion mechanism. Supposing that $N_{1}$ corresponds to the formation of an oxide monolayer at the Pt/YSZ interface and $N_{3}$ to the formation of multilayer, one can estimate the diffusion length $L_{\mathrm{t}}$ at a given time from $L_{\mathrm{t}}=\mathrm{d} N_{3}\left(t_{\mathrm{h}}\right) / N_{1}$, where $N_{3}\left(t_{\mathrm{h}}\right)$ is the amount of oxygen atoms in the multilayer at time $t_{\mathrm{h}}, N_{1}$ is the amount of oxygen atoms in the monolayer at the Pt/YSZ interface $\left(6.6 \times 10^{14}\right.$ atom $)$ and $d$ is the average thickness of an oxide layer $\left(2.7 \times 10^{-10} \mathrm{~m}\right.$, estimated with the Pt-Pt atomic distance [12]). Knowing the diffusion length as a function of time, a diffusion coefficient of $D=3 \times 10^{-22} \mathrm{~m}^{2} \mathrm{~s}^{-1}$ is calculated. This value is typical for a diffusion process in a solid phase and is in good agreement with prediction [13] for the diffusion of oxygen inside platinum at the experimental temperature of $450{ }^{\circ} \mathrm{C}$.

\subsection{Catalytic measurements}

The rate of the catalytic combustion of ethylene with oxygen over the Pt/YSZ catalyst at $525{ }^{\circ} \mathrm{C}$ was measured

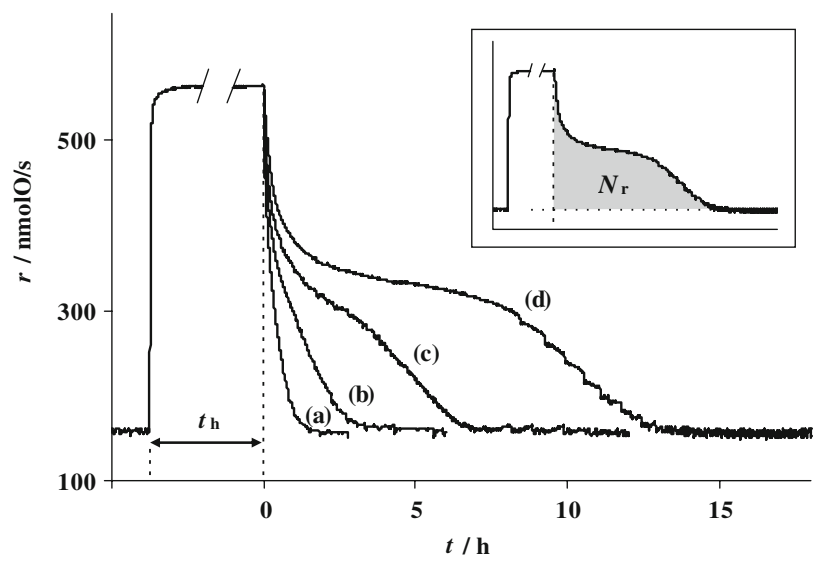

Fig. 7 Ethylene oxidation on Pt/YSZ catalyst. Dependence of the rate transients observed during open-circuit relaxation on the anodic polarization time, $t_{\mathrm{h}}$ : (a) $1 \mathrm{~h}$, (b) $2 \mathrm{~h}, \quad$ (c) $4 \mathrm{~h}$, (d) $11 \mathrm{~h}$. $E_{\mathrm{WR}}=+400 \mathrm{mV}, T=525{ }^{\circ} \mathrm{C}$. Feed composition: $p_{\mathrm{C}_{2} \mathrm{H}_{4}}=0.25$ $\mathrm{kPa}, p_{\mathrm{O}_{2}}=1 \mathrm{kPa}$. The inset shows schematically the integrated amount of oxygen species, $N_{\mathrm{r}}$, consumed via ethylene combustion after current interruption

in an ethylene/oxygen mixture of slightly oxidizing composition. Potentiostatic anodic polarization at $E_{\mathrm{WR}}=400$ $\mathrm{mV}$ was applied for varying holding times, $t_{\mathrm{h}}$, and polarization and relaxation transients of the catalytic reaction rate were recorded, as shown in Fig. 7. Initially the catalyst is under open-circuit conditions and the unpromoted rate is $r_{\mathrm{o}}=150 \mathrm{nmol} \mathrm{O} \mathrm{s}^{-1}$. Once a positive catalyst potential is applied, the rate immediately starts increasing. The time needed for the catalytic rate to reach its new electropromoted steady-state value at $r=560$ nmol $\mathrm{O} \mathrm{s}^{-1}$ is approximately $1 \mathrm{~h}$. The rate enhancement ratio is $\rho=3.5$ and the Faradaic efficiency is $\Lambda=160$. Once the steady-state rate is reached, it remains constant whatever the duration of prolonged anodic polarization. However, a remarkable effect of the polarization time, $t_{\mathrm{h}}$, is observed when the circuit is opened ( $t=0$ in Fig. 7). After short polarization $\left(t_{\mathrm{h}}=1 \mathrm{~h}\right)$ the open-circuit catalytic activity drops abruptly and reaches its initial value in $1.8 \mathrm{~h}$ after current interruption as in any typical EPOC experiment. In contrast, by increasing the polarization time, longer and longer relaxation is required to attain the initial catalytic activity. For instance, after a polarization as long as $t_{\mathrm{h}}=11 \mathrm{~h}$ a relaxation time of $13 \mathrm{~h}$ is necessary for the catalytic activity to return to its initial value. As seen, the effect of polarization time, $t_{\mathrm{h}}$, is only observed when the circuit is opened. Indeed, the shape of the relaxation transient depends greatly on $t_{\mathrm{h}}$, but it has no effect on the electropromoted steady-state reaction rate during the polarization step. Consequently, polarization at long $t_{\mathrm{h}}$ must influence a part of the system which is not exposed to the catalytic reaction. At current interruption this hidden influence becomes visible, so the species 
implicated must somehow reach the active catalytic surface of the system.

\section{Discussion}

The pseudocapacitive behavior of the $\mathrm{O}_{2(\mathrm{~g})}, \mathrm{Pt} / \mathrm{YSZ}$ system reveals that Faradaic processes contribute to both the time dependent and the steady-state current observed in chronoamperometry. A possible reaction scheme involving two anodic Faradaic processes is proposed. One of them is oxygen evolution via electrochemical oxidation of $\mathrm{O}^{2-}$ ions (Eq. 1), responsible for the main part of the steady-state current, while the other is electrochemical oxidation of platinum to form $\mathrm{Pt}-\mathrm{O}$ type species (Eq. 2), responsible for charge storage:

$\mathrm{Pt}+\mathrm{O}^{2-} \rightarrow \mathrm{Pt}-\mathrm{O}+2 \mathrm{e}^{-}$

where use of the symbol Pt-O is due to the unknown stoichiometry of the electrochemically formed oxide [14]. The two reaction paths share the same reactant $\mathrm{O}^{2-}$, the charge carrier in the solid electrolyte YSZ.

Charge storage may take place at different locations in the $\mathrm{O}_{2}(\mathrm{~g}), \mathrm{Pt} / \mathrm{YSZ}$ system. First, $\mathrm{O}^{2-}$ originating from the YSZ lattice gets to the Pt electrode to form a platinumoxygen compound by releasing two electrons. The formation of this first oxide layer at the Pt/YSZ binary interface is believed to be at the origin of the first peak observed by linear sweep voltammetry. The process is fairly reversible, and the completion of this oxide layer is rapid requiring about $10 \mathrm{~min}$ holding time at the anodic potential of $+100 \mathrm{mV}$ (see inset of Fig. 6). The saturation amount of the oxide species is $8 \times 10^{15}$ atom $\mathrm{O} \mathrm{cm}^{-2}$ of geometrical surface area. Comparison with the surface density of $\mathrm{Pt}$ $\left(\sim 1 \times 10^{15}\right.$ atom $\left.\mathrm{O} \mathrm{cm}^{-2}\right)$ gives a roughness factor of about 8 .

Due to the formation of a compact and poorly conducting oxide layer, the Pt/YSZ binary interface takes on a blocking character, which renders any further charge transfer through this interface difficult. However, due to build-up of a strong concentration gradient, the accumulating oxygen species may diffuse slowly away from the electron exchange site, following $t^{1 / 2}$ kinetics. The third peak observed by linear sweep voltammetry may be correlated with this slow process, apparently consecutive to the first process, without showing any tendency to saturate even after anodic polarization as long as 2,000 min. It is believed that this process consists of progressive growth of the platinum oxide layer formed at the metal/electrolyte interface during the first process. However, there is no direct experimental evidence about the location of oxygen stored in this solid diffusion-controlled step. One can not exclude the possibility that oxygen is stored in the YSZ in the vicinity of the anodically polarized Pt electrode, and not in the Pt electrode itself.

Finally, charge also may be stored in the form of oxygen species at the $\mathrm{Pt} /$ gas interface via spillover mechanism. Atomic oxygen released at the tpb does not necessarily desorb to the gas phase as molecular oxygen but may be stuck on the metal, the resulting oxygen species spreading out over the gas-exposed surface. This process is well known in heterogeneous catalysis and is considered as the origin of EPOC [3]. The second peak observed in linear sweep voltammetry may well correspond to the reduction of oxygen species populating the gas exposed surface via the inverse reaction of Eq. 1. In fact, the second process of charge storage has a time constant of a few tens of minutes, in good agreement with that commonly observed in EPOC experiments. The area of the second peak tends to saturation at about $6 \times 10^{16}$ atom $\mathrm{O} \mathrm{cm}^{-2}$, which corresponds to partial steady-state coverage of the highly porous $\mathrm{Pt} / \mathrm{gas}$ interface.

This picture is in good agreement with the sacrificial promoter mechanism of electrochemical promotion [3]. According to this mechanism, anodic polarization produces oxygen promoters via (presumably partial) discharge of $\mathrm{O}^{2-}$ arriving from the solid electrolyte. The promoters migrate with their mirror charge and progressively cover the catalyst/gas interface. They increase the work function of the metal and consequently weaken the catalyst-O bond of chemisorbed oxygen atoms, which leads to an increase in the catalytic activity. As postulated in the state-of-the-art sacrificial promoter model of EPOC, the electrochemically produced backspillover species are consumed both by reaction with the reactant (ethylene) and by desorption. When balance between electrochemical production and consumption is reached, the electropromoted rate of the catalytic reaction (ethylene oxidation in the present case) reaches a steady-state and remains constant during the whole polarization period, meaning that no further alteration of the catalyst/gas interface occurs. However, as shown in Fig. 7, during this apparent steady-state period, the polarization still alters the system, without concerning directly the gas-exposed catalyst surface. The change must then occur at another location of the system, 'hidden' from the gas phase. The very fascinating feature is that the hidden change only affects the catalytic activity once the circuit is opened. It only affects the relaxation transient. The very long characteristic times of this effect indicate that the hidden change is linked to very slow processes, even at high temperatures.

The persistent enhancement of catalytic activity after current interruption is believed to be linked to the charge storage observed through the previous electrochemical investigations, and a mechanism is proposed involving oxygen storage under polarization (Eq. 2) and consumption 
of stored oxygen by the hydrocarbon during relaxation at open-circuit (Eq. 3).

$6 \mathrm{Pt}-\mathrm{O}+\mathrm{C}_{2} \mathrm{H}_{4} \rightarrow 2 \mathrm{CO}_{2}+2 \mathrm{H}_{2} \mathrm{O}+6 \mathrm{Pt}$

Since the Pt-O species are produced electrochemically according to reaction (2), the maximum amount of oxygen, $N_{\mathrm{F}}$, which could be stored during the total polarization period, $t_{\mathrm{h}}$, in the case of a hypothetical $100 \%$ charge storage yield is calculated with Faraday's law:

$N_{\mathrm{F}}=I t_{\mathrm{h}} / 2 \mathrm{~F}$

where $I$ is the current passing through the cell during polarization. Obviously, the actual charge storage yield is surely very much less than $100 \%$; e.g. in the $\mathrm{O}_{2}(\mathrm{~g}), \mathrm{Pt} / \mathrm{YSZ}$ system with a polarization potential of $+100 \mathrm{mV}$ at $450{ }^{\circ} \mathrm{C}$ it was in the order of a few \% (see above). In fact, the effective oxygen storage represents only a fraction of $N_{\mathrm{F}}$ because the majority of the electro-generated oxygen either desorbs in the gas phase as $\mathrm{O}_{2}$ or, in the presence of a reactant like ethylene, is consumed in the catalytic reaction. On the other hand, the amount of oxygen species, $N_{\mathrm{r}}$, consumed via reaction (Eq. 3) after current interruption can be calculated by integrating the area between the relaxation transient curve and the base line given by the unpromoted catalytic rate (see the inset of Fig. 7).

One can then define the oxygen storage efficiency, $\Lambda_{\mathrm{OS}}$, as the ratio between the amount of oxygen consumed by reaction with ethylene, $N_{\mathrm{r}}$, and the maximum amount of electrochemically stored oxygen. Values of $\Lambda_{\mathrm{OS}}$ higher than unity would mean that the effect of stored oxygen on the catalytic reaction rate is non-Faradaic. Assuming a total storage of the species electrochemically produced, a minimum value of $\Lambda_{\mathrm{OS}}$ is calculated as:

$\Lambda_{\mathrm{OS}}=N_{\mathrm{r}} / N_{\mathrm{F}}$

Obviously, when calculated with $N_{\mathrm{F}}$ in Eq. $5, \Lambda_{\mathrm{OS}}$ is highly underestimated.

The oxygen storage efficiency, $\Lambda_{\mathrm{OS}}$, has been calculated with Eq. 5 at different polarization times. Although highly underestimated, values of $\Lambda_{\mathrm{OS}}$ between 40 and 70 are found, significantly exceeding the critical value of one. This means that the rate enhancement after current interruption is not simply due to the consumption of the stored oxygen species by ethylene (Eq. 3), but the effect of stored oxygen on the catalytic reaction rate is highly nonFaradaic.

\subsection{Model of P-EPOC related to oxygen storage}

An interpretation of the phenomenon of permanent electrochemical promotion (P-EPOC) is now attempted. Electrochemical experiments revealed oxygen storage at three different locations in the Pt/YSZ cell when subjected

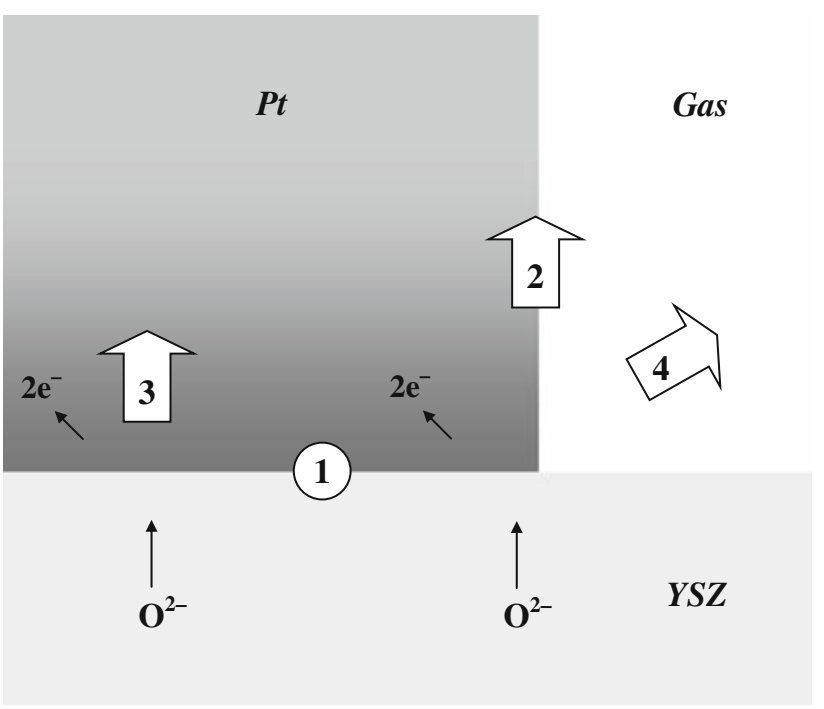

Fig. 8 Scheme of the destiny of Pt-O species produced electrochemically under anodic polarization. Storage at three different locations: (1) at the Pt/YSZ interface, (2) at the gas-exposed catalyst surface via backspillover and (3) in the bulk platinum at the vicinity of the Pt/YSZ interface via solid state diffusion. Leaving (via $\mathrm{O}_{2}$ evolution and/or chemical reaction) toward the gas phase is also indicated (4)

to prolonged anodic polarization. P-EPOC, observed with $\mathrm{Pt} / \mathrm{YSZ}$ catalyst in ethylene oxidation under similar conditions is proposed to be related to oxygen storage according to the following model.

Oxygen storage under anodic polarization is schematized in Fig. 8. At the beginning of anodic polarization, oxygen is stored in a monolayer formed at the catalyst/YSZ interface (1). The amount of this species saturates at short polarization times (10 min for Pt/YSZ), due to the limited amount of storage sites at this interface. Located at a hidden interface, this species has no direct effect on the catalytic reaction rate.

The second type of oxygen storage in the form of backspillover species takes place at the catalyst/gas interface (2) and causes, in principle, reversible electrochemical promotion of catalysis (EPOC). The amount of this species was found to saturate after a certain time of anodic polarization, in good agreement with the polarization time needed to reach the promoted steady-state.

The third type of stored oxygen, appearing consecutively to the saturation of the first species, is attributed to the growth of the oxide layer toward the bulk of the catalyst phase (3). The amount of this species does not saturate even at polarization times as long as 2,000 min, indicating a very large storage capacity, and after an induction period of a few minutes it was found to obey a $t^{1 / 2}$ kinetic law, typical for diffusion-controlled processes.

When the current is switched off, the promoters stored at the gas-exposed surface are consumed by the reaction with 


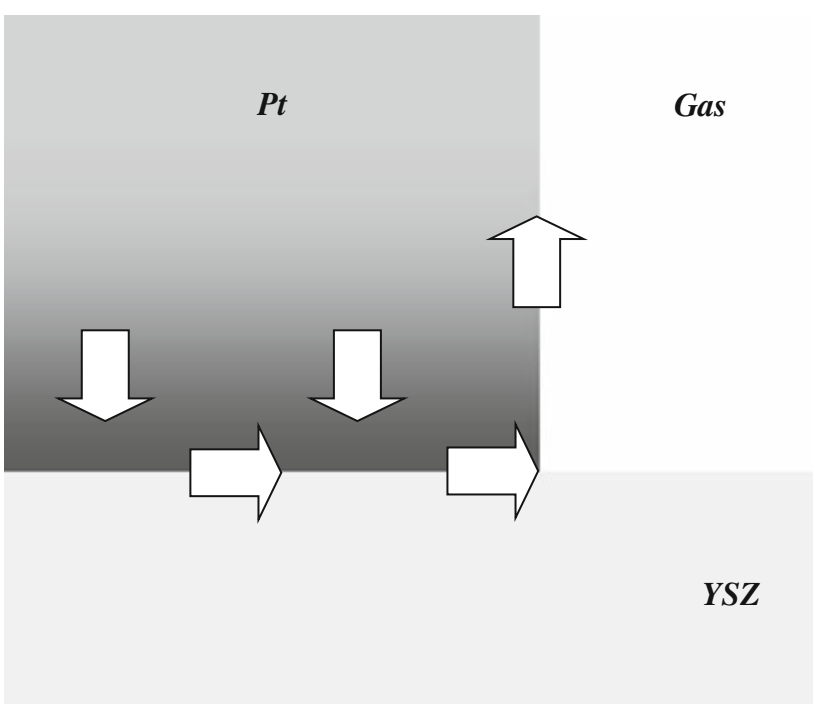

Fig. 9 Scheme of the path of reappearance of the anodically generated hidden $\mathrm{Pt}-\mathrm{O}$ promoters during open-circuit relaxation after current interruption

ethylene and a decrease in the catalytic activity is observed. As Fig. 9 illustrates, the stored oxygen, located inside the catalyst phase is released at the tpb via solid state diffusion and spills over the gas-exposed catalyst surface to contribute to a highly non-Faradaic extent to the persistent enhancement of the reaction rate after current interruption (P-EPOC).

\section{Conclusion}

The effect of anodic polarization of a platinum electrode deposited on YSZ solid electrolyte was studied in $\mathrm{O}_{2^{-}}$ containing atmosphere by electrochemical methods. It was found that prolonged anodic polarization causes, in parallel to the reaction of oxygen evolution, storage of $\mathrm{Pt}-\mathrm{O}$ species at various locations of the electrode, not only at the gasexposed platinum surface but also at other hidden phases and/or interfaces. These charging/discharging processes are responsible for the pseudocapacitive behavior of the electrode. Linear sweep voltammetric measurements indicated that, upon anodic polarization, at least three types of $\mathrm{Pt}-\mathrm{O}$ species were stored, following distinct kinetics. Based on the effect of the polarization time on the amount of the stored $\mathrm{Pt}-\mathrm{O}$ species, they were attributed to three different locations on the electrode: (1) at the Pt/YSZ interface, (2) diffusing from the tpb toward the Pt/gas interface, (3) diffusing from the Pt/YSZ interface toward the bulk of the platinum electrode.
In reactive atmosphere, the catalytic activity of Pt/YSZ may be enhanced strongly by application of anodic potential (EPOC). After prolonged anodic polarization, an unusual long-lasting relaxation of the reaction rate of ethylene oxidation was observed (P-EPOC). For the interpretation of this phenomenon, a model is proposed relating EPOC with oxygen storage at various locations in the $\mathrm{O}_{2(\mathrm{~g})}, \mathrm{Pt} / \mathrm{YSZ}$ system. According to this model, anodic polarization produces $\mathrm{Pt}-\mathrm{O}$ species. The majority of these species is released at the tpb, spills over the catalyst/gas interface and promotes the catalytic activity as done in any reversible EPOC experiment. In parallel, $\mathrm{Pt}-\mathrm{O}$ species are continuously formed at the Pt/YSZ interface to be stored at two distinct locations, either in situ or in the neighboring $\mathrm{Pt}$ phase reached by solid state diffusion, both being hidden from the reactive gas phase. When the polarization is switched off, these hidden oxygen species reappear at the tpb, spread out over the gas-exposed surface and cause non-Faradaic promotion, as any electrochemically formed backspillover oxygen does. The large amount of stored charge and its slow diffusion-controlled emergence causes the rate enhancement to last for hours.

Acknowledgement Financial support from the Fonds National Suisse de la Recherche Scientifique is gratefully acknowledged.

\section{References}

1. Vayenas CG, Bebelis S, Neophitides S (1988) J Phys Chem 92:5083

2. Vayenas CG, Bebelis S, Ladas S (1990) Nature 343:625

3. Vayenas CG, Bebelis S, Pliangos C, Brosda S, Tsiplakides D (2001) electrochemical activation of catalysis: promotion, electrochemical promotion and metal-support interactions. Kluwer Academic/Plenum Publishers, New York

4. Nicole J, Tsiplakides D, Wodiunig S, Comninellis Ch (1997) J Electrochem Soc 144:L312

5. Wodiunig S, Patsis V, Comninellis Ch (2000) Solid State Ionics $136: 813$

6. Foti G, Lavanchy O, Comninellis Ch (2000) J Appl Electrochem 30:1223

7. Jaccoud A, Foti G, Wüthrich R, Jotterand H, Comninellis Ch (2007) Top Catal 44:409

8. Jaccoud A, Falgairette C, Foti G, Comninellis Ch (2007) Electrochim Acta 52:7927

9. Foti G, Jaccoud A, Falgairette C, Comninellis C (2008) J Electroceram. doi:10.1007/s10832-007-9352-7

10. Jaccoud A, Foti G, Comninellis C (2006) Electrochim Acta 51:1264

11. Hendriks MGHM, ten Elshof JE, Bouwmeester HJM, Verweij H (2002) Solid State Ionics 146:211

12. Markusse AP, Kuster BFM, Koningsberger DC, Marin GB (1998) Catal Lett 55:141

13. Velho LR, Barlett RW (1972) Metall Trans 3:65

14. Berry RJ (1978) Surf Sci 76:415 